\title{
Sublobar resection versus lobectomy in solid-type, clinical stage IA, non-small cell lung cancer
}

\author{
Hyun Woo Jeon', Young-Du Kim², Kyung Soo Kim², Sook Whan Sung ${ }^{2}$, Hyung Joo Park² and Jae Kil Park ${ }^{2 *}$
}

\begin{abstract}
Background: Recent studies have demonstrated that sublobar resection is not inferior to lobectomy for peripheral early lung cancer with ground-glass opacification. However, the effect of sublobar resection on solid-type early lung cancer is controversial. The aim of this study was to compare clinical outcomes of patients who have undergone sublobar resection or lobectomy for solid-type, early-stage, non-small cell lung cancer (NSCLC).

Methods: This study was a retrospective review of the records of patients who underwent lobectomy or sublobar resection between March 2000 and September 2010 for clinical stage IA NSCL. Patients with pure ground-glass opacities or death within 30 days after surgery were excluded. Disease-free interval, survival, and prognostic factors were analyzed.

Results: Thirty-one patients and 133 patients underwent sublobar resection and lobectomy, respectively. There were significant differences in age $(P<0.001)$, cardiovascular disease $(P=0.001)$, and diffusing capacity of the lung for carbon monoxide (DLCO) $(P<0.001)$. The patients with lobectomy had a significantly longer disease-free interval $(P<0.001)$ and survival $(P=0.001)$. By multivariate analysis, sublobar resection $(P=0.011)$, lymphatic vessel invasion $(P=0.006)$, and number of positive lymph nodes $(P=0.028)$ were predictors for survival. Sublobar resection $(P<0.001)$, visceral pleural invasion $(P=0.002)$, and lymphatic vessel invasion $(P<0.001)$ were predictors for disease-free interval.
\end{abstract}

Conclusions: Lobectomy should remain the standard surgical procedure for solid-type, clinical stage IA, NSCLC.

Keywords: Non-small cell lung cancer, Sublobar resection, Clinical stage IA

\section{Background}

Lung cancer is the most common cause of cancerrelated death worldwide. Surgical resection for stage IA, non-small cell lung cancer (NSCLC) is the best option for curative treatment, with a 5-year survival rate approaching $70 \%$. Lobectomy with mediastinal lymph node dissection has been considered standard treatment. However, some early-stage patients undergo sublobar resection because of poor cardiopulmonary reserve or other medical comorbidities. Sublobar resection consists of segmentectomy or wedge resection with or without lymph node dissection.

For ground-glass opacities on imaging, which have been found to be slowly growing and noninvasive tumors [1],

\footnotetext{
*Correspondence: jaekpark@catholic.ac.kr

${ }^{2}$ Department of Thoracic and Cardiovascular Surgery, Seoul St. Mary's

Hospital, College of Medicine, The Catholic University of Korea,

222 Banpo-daero, Seocho-gu, Seoul 137-701, Republic of Korea

Full list of author information is available at the end of the article
}

sublobar resection is not inferior to lobectomy. However, in solid-type or solid-dominant early lung cancer, the efficacy of sublobar resection is controversial. Several studies have revealed that sublobar resection was associated with poor outcomes and higher recurrence rates [2,3]. However, because of advances in imaging study and surgical technique, sublobar resection is a reasonable approach for patients with early lung cancers that are $2 \mathrm{~cm}$ or smaller by recent study [4]. We studied the clinical outcomes of patients with solid-type early lung cancers who underwent sublobar resection or lobectomy.

\section{Methods \\ Patients}

This was a retrospective review that was approved by the Institutional Review Board at the Seoul St. Mary's Hospital (Republic of Korea). Between March 2000 and September 2010, 204 patients had clinical stage IA 
NSCLC, according to the 7th edition of the TNM classification for lung cancer. Patients with ground-glass opacity on imaging, a tumor with predominant ground-glass opacification, or who died within 30 days after surgery were excluded. A total of 38 patients showed groundglass opacity or ground-glass opacity dominant lesion (GGO >50\%) on chest tomography. Two patients died from pneumonia and acute respiratory distress syndrome after operation. A total of 164 patients were included in the study. Preoperative assessments included chest computed tomography $(\mathrm{CT})$, abdominal $\mathrm{CT}$, brain magnetic resonance imaging (MRI) and bone scanning with neck sonography. Since 2004, the routine preoperative assessment has included chest $\mathrm{CT}$, positron emission tomography (PET)-CT, bone scanning, brain MRI, and bronchoscopy. Thirty-one patients underwent sublobar resection, and 133 patients underwent lobectomy. Sublobar resection was considered for severe underlying lung disease (interstitial lung disease, obstructive lung disease), poor cardiac function (valvular heart disease, coronary disease), aortic dissection or aneurysm and other underlying malignancy. Of patients undergoing sublobar resection, 12 patients underwent segmentectomy, and 19 patients underwent wedge resection with or without lymph node dissection. Pathologic features and clinical outcomes were compared between the two patient groups. Recurrence was defined as local or extrathoracic metastasis and was based on clinical and pathological evidence. Patients with pathologic stage II or III received adjuvant chemotherapy or chemoradiotherapy. The patients with sublobar resection received radiotherapy if the resected margin was positive.

\section{Statistical analysis}

All statistical analyses were carried out using SPSS version 18 (SPSS Inc., Chicago, USA). Continuous variables were compared using the Mann-Whitney $U$ test, and categorical variables were compared using the Chi-square test and the Fisher exact test. Disease-free intervals and overall survival rates were estimated using the Kaplan-Meier method and compared using the log-rank test. Variables associated with recurrence and survival were determined using the Cox proportional hazards model. Before application of the Cox proportional hazards model, the proportionality assumption was checked. Multivariate analysis for disease-free interval and survival was also performed using the Cox proportional hazards model. Variables with a $P$ value less than 0.05 by univariate analysis were finally evaluated by multivariate analysis using forward selection.

\section{Results}

Records of a total of 164 patients were reviewed in this study. High-risk patients tended to undergo sublobar resection (Table 1). Sublobar resection was significantly associated with older age, more cardiovascular disease $(P=0.001)$, and low diffusing capacity of the lung for carbon monoxide (DLCO). The mean age of lobectomy patients and sublobar resection patients was 62.53 and 69.65 years, respectively $(P<0.001)$. Eight patients $(6 \%)$ with cardiovascular disease underwent lobectomy, and nine patients (29\%) underwent sublobar resection. DLCO was significantly lower in the sublobar resection patients $(P<0.001)$.

Pathologic variables are listed in Table 2. Adenocarcinoma was the most common tumor cell type; however, the fraction of adenocarcinomas was significantly higher in the lobectomy patients $(P=0.012)$. There was no significant difference in the degree of tumor differentiation between the two groups. The mean tumor size of the lobectomy and sublobar resection patients was $2.19 \mathrm{~cm}$ and $1.99 \mathrm{~cm}$, respectively $(P=0.239)$. Among lobectomy patients, the mean bronchial margin was 3.51 , and among sublobar resection patients, the mean margin was $0.95 \mathrm{~cm}(P<0.001)$. The number of excised lymph nodes was significantly higher in the lobectomy group $(P<0.001)$. Twenty patients with lobectomy $(15 \%)$ had pathologic nodal disease $(P<0.015)$. The number of positive lymph nodes was significantly higher in the lobectomy patients $(P=0.019)$. Although the number of metastatic mediastinal lymph nodes was higher in the lobectomy patients, the difference was not significant. There was no significant difference in the numbers of

Table 1 Baseline patient characteristics

\begin{tabular}{llll}
\hline Characteristic & $\begin{array}{l}\text { Lobectomy } \\
(\mathbf{N}=133) \\
\text { Mean } \pm \text { SD } \\
\text { or } \mathbf{n}(\%)\end{array}$ & $\begin{array}{l}\text { Sublobar resection } \\
(\mathbf{N}=31)\end{array}$ & $\begin{array}{l}\boldsymbol{P} \text { value } \\
\text { or } \mathbf{n}(\%)\end{array}$ \\
\hline Age & $62.53 \pm 9.12$ & $69.65 \pm 10.94$ & $<0.001$ \\
Sex male & $83(62.41)$ & $22(70.97)$ & 0.413 \\
Hypertension & $49(36.84)$ & $14(45.16)$ & 0.417 \\
Diabetes mellitus & $19(14.29)$ & $8(25.81)$ & 0.175 \\
Cardiovascular disease & $8(6.02)$ & $9(29.03)$ & 0.001 \\
Cerebrovascular accident & $3(2.26)$ & $3(9.68)$ & 0.082 \\
Interstitial lung disease & $11(8.27)$ & $11(19.35)$ & 0.096 \\
COPD & $6(4.51)$ & $4(12.90)$ & 0.096 \\
FEV1 & $2.41 \pm 0.57$ & $2.16 \pm 0.66$ & 0.087 \\
DLCO & $98 \pm 19.78$ & $75 \pm 15.88$ & $<0.001$ \\
PET SUVmax & $4.81 \pm 3.41$ & $5.85 \pm 4.45$ & 0.386 \\
\hline
\end{tabular}

Data presented as the mean (standard deviation) or frequencies and percentages as appropriate.

COPD, chronic obstructive pulmonary disease; DCLO, diffusing capacity of the lung for carbon monoxide; FEV1, forced expiratory volume-one second; PET SUVmax, maximum standardized uptake value on positron emission tomography. Data presented as mean \pm SD or $\mathrm{n}(\%)$ as appropriate. Continuous variables were compared using Mann-Whitney $U$ test and categorical variables were tested using Chi-square test or Fisher exact test. 
Table 2 Pathologic data of solid-type, clinical stage IA, non-small cell lung cancers

\begin{tabular}{|c|c|c|c|}
\hline \multirow[t]{2}{*}{ Variables } & $\begin{array}{l}\text { Lobectomy } \\
(\mathrm{N}=133)\end{array}$ & $\begin{array}{l}\text { Sublobar resection } \\
(\mathrm{N}=31)\end{array}$ & \multirow[t]{2}{*}{$P$ value } \\
\hline & $\begin{array}{l}\text { Mean } \pm \text { SD } \\
\text { or } n(\%)\end{array}$ & $\begin{array}{l}\text { Mean } \pm \text { SD } \\
\text { or } n(\%)\end{array}$ & \\
\hline Histology & & & 0.012 \\
\hline Adenocarcinoma & $109(82.0)$ & $18(58.1)$ & \\
\hline Squamous & $16(12.0)$ & $10(32.36)$ & \\
\hline Others & $8(6.0)$ & $3(9.7)$ & \\
\hline Differentiation & & & 0.116 \\
\hline Well & $51(38.4)$ & $6(19.4)$ & \\
\hline Moderate & $65(48.9)$ & $21(67.7)$ & \\
\hline Poor & $17(12.8)$ & $4(12.9)$ & \\
\hline Tumor size & $2.19 \pm 0.75$ & $1.99 \pm 0.75$ & 0.239 \\
\hline p T stage & & & 0.694 \\
\hline pT1a & $67(50.4)$ & $17(54.8)$ & \\
\hline Margin & $3.51 \pm 2$ & $0.95 \pm 1.16$ & $<0.001$ \\
\hline Positive margin & $1(0.8)$ & $7(22.6)$ & $<0.001$ \\
\hline Visceral pleural invasion & $15(11.3)$ & $3(6.7)$ & 1.000 \\
\hline Lymphatic vessel invasion & $29(21.8)$ & $4(12.9)$ & 0.450 \\
\hline Blood vessel invasion & $3(2.3)$ & $0(0)$ & 1.000 \\
\hline Number of LN harvest & $10.50 \pm 7.6$ & $1.74 \pm 5.09$ & $<0.001$ \\
\hline LN metastasis & $20(15.0)$ & $0(0)$ & 0.015 \\
\hline Number of positive LNs & $0.53 \pm 1.90$ & $0(0)$ & 0.019 \\
\hline N2 positive & $10(7.5)$ & $0(0)$ & 0.211 \\
\hline p Stage & & & 0.156 \\
\hline p Stage I & $112(84.2)$ & $30(96.8)$ & \\
\hline p Stage II & $11(8.3)$ & $0(0)$ & \\
\hline p Stage III & $10(7.5)$ & $1(3.2)$ & \\
\hline Recurrence & $35(26.3)$ & $19(61.3)$ & $<0.001$ \\
\hline Lung to lung metastasis & $8(6)$ & $6(19.4)$ & \\
\hline Margin & $4(3)$ & $4(12.9)$ & \\
\hline Mediastinal lymph node & $6(4.5)$ & $5(16.1)$ & \\
\hline Distant metastasis & $17(12.8)$ & $4(12.9)$ & \\
\hline
\end{tabular}

Data presented as the mean (standard deviation) or frequencies and percentages as appropriate.

$\mathrm{LN}$, lymph nodes. Data presented as mean \pm SD or $\mathrm{n}(\%)$ as appropriate. Continuous variables were compared using Mann-Whitney $U$ test, and categorical variables were tested by Chi-square test or Fisher exact test.

patients with lymphatic vessel invasion, visceral pleural invasion, and blood vessel invasion between the two groups.

All patients were followed until recurrence and death or loss to follow-up $(\mathrm{F} / \mathrm{U})$. The median F/U period for lobectomy and sublobar resection patients was 40 months and 30 months, respectively. There was recurrence in 35 lobectomy patients $(26 \%)$ and 19 sublobar resection patients $(61 \% ; P<0.001)$. Local recurrence rate was also significant higher in the patients with sublobar resection
(7.5\% in lobectomy versus $29 \%$ in sublobar resection; $P<0.001)$. The disease-free interval of lobectomy patients was significantly longer $(P<0.001$; Figure $1 \mathrm{a})$. By univariate analysis, cardiovascular disease, sublobar resection, visceral pleural invasion, positive margin, lymphatic vessel invasion, and lymph node metastasis were significant predictors of recurrence. By multivariate analysis, sublobar resection $(P<0.001)$, visceral pleural invasion $(P=0.002)$, and lymphatic vessel invasion $(<0.001)$ were significant for recurrence (Table 3).

Sublobar resection was associated with high overall mortality. ( $P=0.001$; Figure $1 \mathrm{~b})$. Estimated 5 -year survival rate was $81 \%$ in the lobectomy group and $41 \%$ in the sublobar resection group. Univariate analysis for predictors of survival revealed that age, cardiovascular disease, sublobar resection, lymphatic vessel invasion, number of lymph node metastases, and pathological mediastinal lymph node metastasis were statistically significant. Sublobar resection $(P=0.011)$, lymphatic vessel invasion $(P=0.006)$, and number of metastatic lymph nodes $(P=0.028)$ were significant predictors for overall survival by multivariate analysis (Table 4). Only sublobar resection and lymphatic vessel invasion were significant for both recurrence and survival in our study.

In a subgroup analysis of 83 patients with tumors smaller than $2 \mathrm{~cm}$, lobectomy was significantly associated with better clinical outcomes than sublobar resection (Figure 2). We also evaluated clinical outcomes between segmentectomy and wedge resection in 31 patients with sublobar resections. There was no significant difference for disease-free interval $(P=0.252)$ and survival $(P=0.821)$ between segmentectomy and wedge resection.

There was no significant difference for survival $(P=$ $0.979)$ and disease-free interval $(P=0.707)$ according to tumor size (pT1a versus pT1b) in sublobar resection.

Multivariate analysis after exclusion of the eight patients with incomplete resection demonstrated that sublobar resection was the only independent risk factor for overall survival in subgroup analysis $(P=0.038$, Hazard ratio: $3.01,95 \%$ confidence interval, 1.06 to 8.58 ).

\section{Discussion}

Lung cancer is one of the most common malignant tumors worldwide, with a poor prognosis despite multimodality management [5]. However, 5-year survival rates of up to $70 \%$ have been achieved after surgical treatment for patients with stage I lung cancers [6]. Pneumonectomy, with high morbidity and mortality, was the standard surgical treatment in the 1940s [7]. Since the 1950s, lobar resection plus mediastinal lymph node dissection has become the standard surgical treatment for lung cancer $[8,9]$.

Patients with early lung cancer who are not suitable for lobar resections are a dilemma for thoracic surgeons. Most of these patients are elderly and have poor 

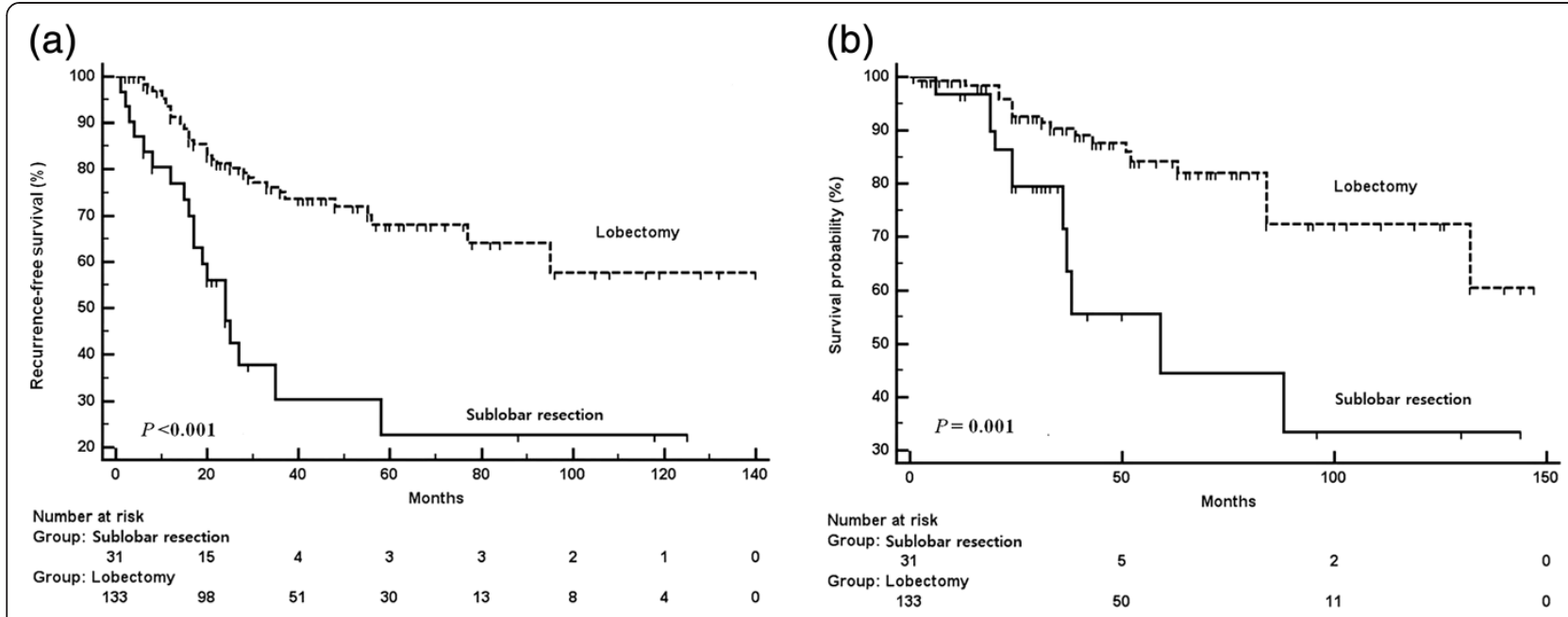

Figure 1 Survival and disease-free intervals of patients undergoing lobectomy and sublobar resection for solid-type, clinical stage IA, non-small cell lung cancers. a. Recurrence-free survival. b. Overall survival.

cardiopulmonary reserve and other medical comorbidities. Sublobar resection has been an alternative treatment, and its efficacy has been evaluated in several studies [10,11]. Ground-glass opacities (GGO) or GGO-predominant lesions on chest CT are features of bronchioloalveolar carcinoma or adenocarcinoma, which are slowly growing and noninvasive tumors [12]. Sublobar resection is appropriate for these lesions [13-15]; however, the efficacy of sublobar resection for solid-type lung cancer is controversial.

In 1995, a randomized trial was performed that compared sublobar resection with lobectomy for clinical early stage NSCLC [2]. Sublobar resection was associated with high rates of recurrence and death. Landreneau et al. compared wedge resection with lobectomy in 1997 [3]. Wedge resection failed to demonstrate equivalent results; however, Kodama et al. demonstrated that sublobar resection with lymph node dissection was not inferior to lobectomy [16]. Because of advances in imaging study, surgical technique and revised TNM classification, the effect of sublobar resection has been evaluated for patients with clinical T1a lung cancers again. Several studies found no difference for recurrence and survival between patients undergoing sublobar resection or lobectomy $[4,17,18]$.
Okada et al. compared segmentectomy with lobectomy for tumors smaller than $2 \mathrm{~cm}$, and found respective 5-year survival rates of $87.1 \%$ and $87.7 \%$ for segmentectomy and lobectomy. In recent study, randomized study was conducted and sublobar resection is not inferior to lobectomy for clinical stage IA lung cancer [19]. The recurrence rate was more common in the patients with sublobar resection but not significantly and the survival was not different in their study.

Our study showed different results. High-risk patients more frequently underwent sublobar resection, and sublobar resection showed shorter disease-free interval and poor survival. Furthermore, 19 patients (61.3\%) in sublobar resection showed recurrence during the follow-up period. Lung to lung metastasis (31.6\%) was most common followed by mediastinal lymph node metastasis $(26.3 \%)$.

Lymph node metastasis is common in solid-type lung cancers [20]. In our study, $15 \%$ of lobectomy patients had lymph node metastases at the time of surgery in clinical stage IA NSCLC. Lymphatic vessel invasion has been found to be a prognostic factor [21]. Lymphatic vessel invasion is associated with lymph node metastasis, recurrence, and decreased survival. Funai et al. reported

Table 3 Univariate and multivariate analyses for predictors of recurrence

\begin{tabular}{|c|c|c|c|c|c|c|}
\hline \multirow[t]{2}{*}{ Variables } & \multicolumn{3}{|c|}{ Univariate } & \multicolumn{3}{|c|}{ Multivariate } \\
\hline & HR & $95 \% \mathrm{Cl}$ & $P$ value & HR & $95 \% \mathrm{Cl}$ & $P$ value \\
\hline Cardiovascular disease & 2.152 & 1.051 to 4.409 & 0.036 & & & \\
\hline Sublobar resection & 3.379 & 1.920 to 5.946 & $<0.001$ & 4.387 & 2.438 to 7.891 & $<0.001$ \\
\hline Visceral pleural invasion & 3.281 & 1.628 to 6.612 & 0.001 & 3.142 & 1.510 to 6.538 & 0.002 \\
\hline Positive margin & 2.692 & 1.148 to 6.314 & 0.023 & & & \\
\hline Lymphatic vessel invasion & 3.308 & 1.853 to 5.908 & $<0.001$ & 3.385 & 1.853 to 6.182 & $<0.001$ \\
\hline Lymph node metastasis & 2.194 & 1.067 to 4.512 & 0.033 & & & \\
\hline
\end{tabular}

$\mathrm{Cl}$, confidence interval; $\mathrm{HR}$, hazard ratio. 
Table 4 Univariate and multivariate analyses for predictors of survival

\begin{tabular}{|c|c|c|c|c|c|c|}
\hline \multirow[t]{2}{*}{ Variables } & \multicolumn{3}{|c|}{ Univariate } & \multicolumn{3}{|c|}{ Multivariate } \\
\hline & $\overline{\mathrm{HR}}$ & $95 \% \mathrm{Cl}$ & $P$ value & $\overline{H R}$ & $95 \% \mathrm{Cl}$ & $P$ value \\
\hline Age & 1.050 & 1.010 to 1.091 & 0.014 & & & \\
\hline Cardiovascular disease & 3.501 & 1.550 to 7.906 & 0.003 & & & \\
\hline Sublobar resection & 3.236 & 1.525 to 6.868 & 0.002 & 3.224 & 1.312 to 7.924 & 0.011 \\
\hline Lymphatic vessel invasion & 3.690 & 1.670 to 8.154 & 0.001 & 3.586 & 1.445 to 8.900 & 0.006 \\
\hline Number of positive LNs & 1.272 & 1.095 to 1.478 & 0.002 & 1.214 & 1.022 to 1.442 & 0.028 \\
\hline N2 positive & 5.123 & 1.716 to 15.297 & 0.003 & & & \\
\hline
\end{tabular}

$\mathrm{Cl}$, confidence interval; HR, hazard ratio; LN, lymph node; N2, mediastinal lymph node.

that lymphatic vessel invasion was an independent prognostic factor for early-stage lung cancers [22].

The proportion of solid component has been correlated with malignant potential regardless of tumor size [23]. Our study results support this finding. Despite the early stages of the solid-type tumors in our study, they had aggressive behavior and were associated with several prognostic pathologic features, including lymphatic vessel invasion, pleural invasion, and occult lymph node metastasis. In our study, sublobar resection failed to demonstrate efficacy, even for tumors smaller than $2 \mathrm{~cm}$. Lobectomy provided longer disease-free-interval and survival. Therefore, lobectomy with lymph node dissection remains standard treatment for patients with solid-type early lung cancers, regardless of tumor size.

Our study had limitations because it was small and nonrandomized, and positive margins were common among the sublobar resections; however, neither recurrence nor survival was associated with positive margins according to multivariate analysis. Okami et al. found that sublobar resection for elderly patients provided good clinical outcomes [24], but we did not compare sublobar resection with lobectomy for high-risk patients, including patients who were older or who had poor cardiopulmonary reserve. Another limitation was that the number of resected lymph nodes evaluated from patients undergoing sublobar resection was significantly lower than the number from lobectomy patients $[25,26]$.

\section{Conclusions}

In conclusion, solid-type lung cancers demonstrated aggressive behavior, and there were numerous significant pathologic prognostic factors in clinical stage IA NSCLC from our study. Lymph node metastasis was common in clinical stage IA NSCLC with a solid component. Lobectomy with lymph node dissection remains the standard surgical procedure for patients with solid-type, clinical stage, IA NSCLC.

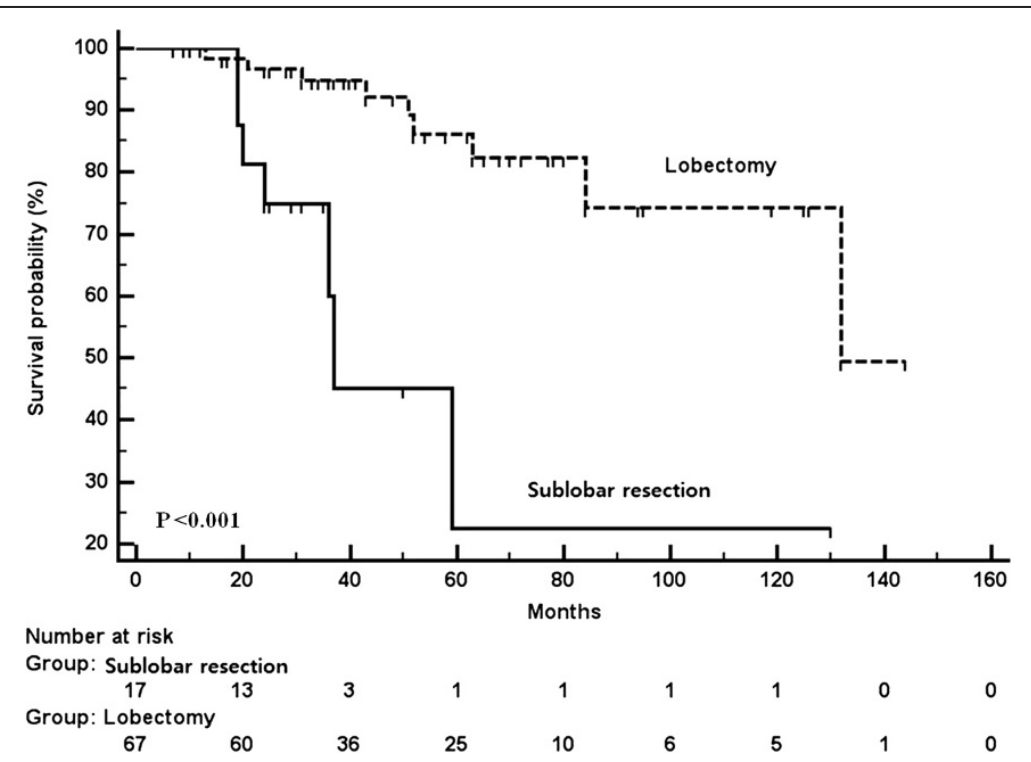

Figure 2 Overall Survival patients undergoing lobectomy and sublobar resection for solid-type, clinical stage IA, non-small cell lung cancers smaller than $2 \mathrm{~cm}$. 


\section{Abbreviations}

CT: computed tomography; DLCO: diffusing capacity of the lung for carbon monoxide; F/U: follow-up; GGO: ground-glass opacity; MRI: magnetic resonance imaging; NSCLC: non-small cell lung cancer; PET: positron emission tomography.

\section{Competing interests}

The authors declare that they have no conflicts of interest or financial ties to disclose.

\section{Author's contributions}

HWJ carried out the review of medical records, analysis and writing. YDK and SWS carried out the revision. KSK carried out the review of medical records. HJP carried out the revision of statistics. JKP carried out the correspondence, revision, and review of medical records. All authors read and approved the final manuscript.

\section{Acknowledgements}

This manuscript has been edited by native English-speaking experts of BioMed Proofreading.

\section{Author details}

'Department of Thoracic and Cardiovascular Surgery, Bucheon St. Mary's Hospital, College of Medicine, The Catholic University of Korea, 327 Sosaro, Wonmi-gu, Bucheon, Republic of Korea. ${ }^{2}$ Department of Thoracic and Cardiovascular Surgery, Seoul St. Mary's Hospital, College of Medicine, The Catholic University of Korea, 222 Banpo-daero, Seocho-gu, Seoul 137-701, Republic of Korea.

Received: 13 August 2013 Accepted: 4 July 2014

Published: 16 July 2014

\section{References}

1. Sakao Y, Miyamoto H, Sakuraba M, Oh T, Shiomi K, Sonobe S, Izumi H: Prognostic significance of a histologic subtype in small adenocarcinoma of the lung: the impact of nonbronchioloalveolar carcinoma components. Ann Thorac Surg 2007, 83:209-214.

2. Ginsberg RJ, Rubinstein LV: Randomized trial of lobectomy versus lilmited resection for T1 N0 non-small cell lung cancer. Lung Cancer Study Group. Ann Thorac Surg 1995, 60:615-622.

3. Landreneau RJ, Sugarbaker DJ, Mack MJ, Hazelrigg SR, Luketich JD, Fetterman L, Liptay MJ, Bartley S, Boley TM, Keenan RJ, Ferson PF, Weyant RJ, Naunheim KS: Wedge resection versus lobectomy for stage I (T1 N0 M0) non-small-cell lung cancer. J Thorac Cardiovasc Surg 1997, 113:691-698.

4. Okada M, Koike T, Higashiyama M, Yamato Y, Kodama K, Tsubota N: Radical sublobar resection for small-sized non-small cell lung cancer: a multicenter study. J Thorac Cardiovasc Surg 2006, 132:769-775.

5. Jemal A, Siegel R, Xu J, Ward E: Cancer statistics, 2010. CA Cancer J Clin 2010, 60:277-300.

6. Strand TE, Rostad H, Moller B, Norstein J: Survival after resection for primary lung cancer: a population based study of 3211 resected patients. Thorax 2006, 61:710-715.

7. Ochsner A, Debakey M: Primary pulmonary malignancy: treatment by total pneumonectomy; analysis of 79 collected cases and presentation of 7 personal cases. Ochsner J 1999, 1:109-125.

8. Cahan WG: Radical lobectomy. J Thorac Cardiovasc Surg 1960, 39:555-572.

9. Scott WJ, Howington J, Feigenberg S, Movsas B, Pisters K: Treatment of non-small cell lung cancer stage I and stage II: ACCP evidence-based clinical practice guidelines (2nd edition). Chest 2007, 132:234S-242S.

10. Jensik RJ, Faber LP, Milloy FJ, Monson DO: Segmental resection for lung cancer. A fifteen-year experience. J Thorac Cardiovasc Surg 1973, 66:563-572.

11. Pastorino U, Valente M, Bedini V, Infante M, Tavecchio L, Ravasi G: Limited resection for Stage I lung cancer. Eur J Surg Oncol 1991, 17:42-46.

12. Noguchi M, Morikawa A, Kawasaki M, Matsuno Y, Yamada T, Hirohashi S, Kondo H, Shimosato Y: Small adenocarcinoma of the lung. Histologic characteristics and prognosis. Cancer 1995, 75:2844-2852.

13. Nakata M, Sawada S, Saeki H, Takashima S, Mogami H, Teramoto N, Eguchi K: Prospective study of thoracoscopic limited resection for ground-glass opacity selected by computed tomography. Ann Thorac Surg 2006, 75:1601-1605.
14. Koike T, Togashi K, Shirato T, Sato S, Hirahara H, Sugawara M, Oguma F, Usuda $\mathrm{H}$, Emura I: Limited resection for noninvasive bronchioloalveolar carcinoma diagnosed by intraoperative pathologic examination. Ann Thorac Surg 2009, 88:1106-1111.

15. Nakayama H, Yamada K, Saito H, Oshita F, Ito H, Kameda Y, Noda K: Sublobar resection for patients with peripheral small adenocarcinomas of the lung: surgical outcome is associated with features on computed tomographic imaging. Ann Thorac Surg 2007, 84:1675-1679.

16. Kodama K, Doi O, Higashiyama M, Yokouchi H: Intentional limited resection for selected patients with T1 N0 M0 non-small-cell lung cancer: a single-institution study. J Thorac Cardiovasc Surg 1997, 114:347-353.

17. Wisnivesky JP, Henschke CI, Swanson S, Yankelevitz DF, Zulueta J, Marcus S, Halm EA: Limited resection for the treatment of patients with stage IA lung cancer. Ann Surg 2010, 251:550-554

18. Kates M, Swanson S, Wisnivesky JP: Survival following lobectomy and limited resection for the treatment of stage I non-small cell lung cancer $<=1 \mathrm{~cm}$ in size: a review of SEER data. Chest 2011, 139:491-496.

19. Altorki NK, Yip R, Hanaoka T, Bauer T, Aye R, Kohman L, Sheppard B, Thurer R, Andaz S, Smith M, Mayfield W, Grannis F, Korst R, Pass H, Straznicka M, Flores $\mathrm{R}$, Henschke Cl: Sulobar resection is equivalent to lobectomy for clinical stage 1A lung cancer in solid nodules. J Thorac Cardiovasc Surg 2014, 147:754-762.

20. Hattori A, Suzuki K, Matsunaga T, Fukui M, Kitamura Y, Miyasaka Y, Tsushima Y, Takamochi K, Oh S: Is limited resection appropriate for radiologically "solid" tumors in small lung cancers? Ann Thorac Surg 2012, 94:212-215.

21. Higgins KA, Chino JP, Ready N, D'Amico TA, Berry MF, Sporn T, Boyd J, Kelsey CR: Lymphovascular invasion in non-small-cell lung cancer: implications for staging and adjuvant therapy. J Thorac Oncol 2012, 7:1141-1147.

22. Funai K, Sugimura H, Morita T, Shundo Y, Shimizu K, Shiiya N: Lymphatic vessel invasion is a significant prognostic indicator in stage IA lung adenocarcinoma. Ann Surg Oncol 2011, 18:2968-2972.

23. Inoue M, Minami M, Sawabata N, Utsumi T, Kadota Y, Shigemura N, Okumura M: Clinical outcome of resected solid-type small-sized c-stage IA non-small cell lung cancer. Eur J Cardiothorac Surg 2010, 37:1445-1449.

24. Okami J, Ito Y, Higashiyama M, Nakayama T, Tokunaga T, Maeda J, Kodama K: Sublobar resection provides an equivalent survival after lobectomy in elderly patients with early lung cancer. Ann Thorac Surg 2010, 90:1651-1656.

25. Narsule CK, Ebright MI, Fernando HC: Sublobar versus lobar resection: current status. Cancer J 2011, 17:23-27.

26. Schuchert MJ, Abbas G, Pennathur A, Nason KS, Wilson DO, Luketich JD, Landreneau RJ: Sublobar resection for early-stage lung cancer. Semin Thoracic Cardiovasc Surg 2010, 22:22-31.

doi:10.1186/1477-7819-12-215

Cite this article as: Jeon et al:: Sublobar resection versus lobectomy in solid-type, clinical stage IA, non-small cell lung cancer. World Journal of Surgical Oncology 2014 12:215.

\section{Submit your next manuscript to BioMed Central and take full advantage of:}

- Convenient online submission

- Thorough peer review

- No space constraints or color figure charges

- Immediate publication on acceptance

- Inclusion in PubMed, CAS, Scopus and Google Scholar

- Research which is freely available for redistribution 